\title{
Fertility Preferences of the Post-1980s Generation in Urban China
}

\author{
Lei Xu \\ Department of Geography, California State University, Fullerton, USA \\ Email: lxu@fullerton.edu
}

Received July $26^{\text {th }}$, 2013; revised September $2^{\text {nd }}, 2013$; accepted September $12^{\text {th }}, 2013$

\begin{abstract}
Copyright (C) 2013 Lei Xu. This is an open access article distributed under the Creative Commons Attribution License, which permits unrestricted use, distribution, and reproduction in any medium, provided the original work is properly cited.
\end{abstract}

\begin{abstract}
Born under the one-child policy and growing up in an environment of tremendous socioeconomic change, the post-1980s generation of China tends to have interesting fertility preferences. This study explores the fertility desire, gender preference, and potential utilization of fetal ultrasound among the post-1980s individuals in urban China, based on a survey conducted in Beijing and Puyang, China. The ideal number of children among the post-1980s was substantially lower than the replacement level. $26 \%$ of the respondents considered China's family planning policies as the most important determinant of their fertility desire, whereas $57 \%$ of the respondents indicated economic factors as the major determinant. With respect to gender preference, nearly half of the respondents who desired one child indicated no preference, and $79 \%$ of those who desired two children preferred 1 boy and 1 girl. In terms of potential utilization of ultrasound, the large majority of the respondents indicated an intention to use ultrasound to check the wellness of the fetus. Nearly half of them wanted to know the gender of the fetus via ultrasound examination, which is illegal in China. The findings imply that urban China has been experiencing a transition from a top-down governmental promoted fertility decline to a bottom-up individual voluntary choice of low fertility. In the context of below replacement fertility and population ageing, step-by-step relaxations of the family planning policies may lead to a small, gradual, and beneficial fertility increase.
\end{abstract}

Keywords: China; Post-1980s Generation; Fertility Desire; Ideal Parity; Gender Preference; Family Planning

\section{Introduction}

It has been over four decades since Mainland China (hereafter China) implemented its series of family planning policies. The “wan-xi-shao 晚-稀-少” (i.e. later-longer-fewer) policy was introduced in 1970 aiming to reduce China's fertility level. Although it was not mandatory, the policy strongly encouraged people to have later marriages, longer child spacing and fewer children. This policy helped to reduce the total fertility rate (TFR) substantially from 5.8 to 2.75 (Liang \& Lee, 2006). In 1979 the so-called "one-child policy" was officially introduced by the Chinese government. China's TFR further declined from 2.75 in 1979 to 1.49 in 1998 . When the national policy was implemented by the local governments and family-planning committees in different regions of China, it created highly localized manifestations and features (Gu et al., 2007). In general, the policy was strictly enforced in the eastern, coastal regions, moderately enforced in the central regions, and relaxed in the western regions (Zhu, Lu, \& Hesketh, 2009). It was particularly strictly enforced in urban areas of China. The number of children for each couple was closely monitored and recorded by the household registration system (i.e. hukou 户口). Although there were exceptions for ethnic minorities, couples whose first child is seriously disabled, and other special cases, the vast majority of urban residents of China were subject to the one-child-per-family rule. Adherence to the rule would lead to social and economic benefits, such as priority status for schools and housing, honor certificates, and monthly food subsidies, while break of the rule would result in monetary penalty and even a demotion, which was particularly true for government workers and officials as well as workers of state-owned enterprises (Veeck et al., 2011). Thus the TFR in urban China was very low-it decreased to 1.13 by 1998 , compared to 1.52 in rural China (Liang \& Lee, 2006). It is clear that fertility behaviors of the Chinese people have changed dramatically, either involuntarily or voluntarily. Furthermore, the gender imbalance of China's new generations is stunning. In the Chinese traditional Confucian ideology, the continuation of family line is through male descendants, who take family pride and provide labor and old-age security for their parents (Arnold \& Liu, 1986; Wang, 2005; Yan, 2003; Zeng et al., 1993; Zhang, Feng, \& Zhang, 2006). The traditional son preference, combined with the implementation of the family planning programs and availability of sex selection technologies such as ultrasound, might have resulted in sex-selective abortions in China (Chu, 2001). The sex ratio at birth increased since 1980s. It was 117 (i.e. 117 males per 100 females) in 2000, and was particularly high in rural areas where couples were allowed to have a second child if their first one was a girl (Zhu, Lu, \& Hesketh, 2009). An obvious consequence of high sex ratio at birth is an imbalance between the sexes in future marriage opportunities. The State Population and Family Planning Commission predicted that 
there would be more than 30 million "surplus" males in the 20 45 age interval in 2020 (Zeng, 2007), which will lead to "marriage squeeze" and bring substantial social issues.

The timing of the "one-child policy" initiation was just about the introduction of China's "open door policy”, announced by Deng Xiaoping in December 1978. Since then, China's economy grew at substantially high rates, accompanied with significant sociocultural changes. It seemed that many of the middle-class individuals, especially those in urban China, started to reduce their fertility voluntarily as the "opportunity cost" of having children increased. Under the circumstances of economic, sociocultural and political changes, research on the changing attitude in fertility among Chinese young people is important, yet very limited in the literature. With few exceptions (e.g. Whyte \& Gu, 1987; Zhang et al., 2006), most research on China's fertility issues examined the actually fertility rather than desired fertility. This research aims at investigating the fertility preferences of the post-1980s generation in urban areas of China. Specifically, the study seeks the answers to such questions as how many children are desired and why, whether the traditional strong preference for male descendants still hold true for China's new generation of "parents", whether a change in population policy affect the fertility desire of the younger generation, and how ultrasound technology will be utilized during childbearing. The post-1980s generation is referred to as the individuals who were born between 1980 and 1989. They are the "product" of China's one child policy, rapid economic development, and tremendous social changes. The post-1980s are now in their marriage and reproductive ages. Their fertility preferences on the number and gender of their future children will shed some light on the future fertility level of China. They will also provide insightful policy implications on the possible adjustment and revision of China's family planning programs.

\section{Description of Sample}

This study is based on a questionnaire survey conducted in June-December 2010 in two cities-Beijing and Puyang. Beijing is China's capital city, located in North China. It is China's political, cultural and educational center as well as economic and financial management center. The city of Puyang, Henan province is located in central China. It is a mediumsized city based on petrochemical industries. The two cities were selected for covering the post-1980s in both large international metropolis and interior middle-sized city, and for investigating differences between the two. In total, 828 individuals responded the survey.

The survey collected data on a wide range of personal attributes such as migrant/non-migrant status, urban or rural hukou registration, age, gender, marital status, educational attainment, employment, socioeconomic status, and parental family size. The questionnaire asked questions on ideal parity (i.e. ideal number of children), gender preference, intention to utilize fetal ultrasound, and the underlying reasons for the fertility preferences. Cross-tabulation was used to analyze the data and discover pattern. The questionnaire also contained quite a few open-ended questions, to gain insights on the fertility behaviors of the respondents. Having a child might change one's fertility desire and gender preference afterwards, so the questionnaire asked different sets of questions for individuals who already had children versus those who had not.

With respect to the demographic profile of the sample, the post-1980s (i.e. those whose age lied between 21 and 30 at the time of the survey) represented $59.9 \%$ of the sampled individuals. In terms of educational attainment, the vast majority of the respondents were high school graduates, and $56.5 \%$ of the respondents had Bachelor's degree or above (Table 1).

With respect to sex composition, 56.4\% were females and $43.6 \%$ were males. The sample was slightly female dominant, probably because young women were more likely to participate in survey and/or were more interested in the research topic than young men. In terms of household registration status, $79 \%$ of the respondents had urban registration whereas as $21 \%$ were under rural registration. Around $60 \%$ of the individuals were non-migrants (i.e. permanent residents of the city), and $40 \%$ were migrants. About self-perceived economic status, $67 \%$ considered themselves as "good", 17\% indicated "very good", and $15 \%$ of them thought their economic conditions were "not so good". $44.6 \%$ of the sampled individuals were the only child of their family, and $8 \%$ of the respondents were ethnic minorities.

\section{Main Findings}

\section{Ideal Parity}

This research revealed that the ideal parity among the post-1980s generation was far below the replacement level (i.e. 2.1). For those who did not have children, the ideal parity was as low as 1.26 , with a $95 \%$ standard error being .05 . When comparing the age groups 21 - 25 and 26 - 30, the respective ideal parities were not significantly different.

The results also suggested that the desired number of children was about the same between the migrants and non-migrants (Table 2). Moreover, there were no apparent differences in ideal parity with respect to different genders, educational attainment, household registration status, being the only child or not, employment status, and self-perceived economic status. However, significant difference in ideal parity was discovered between ethnic minorities (1.09) and non-minorities (1.27).

Table 1.

Age and educational attainment of the sampled individuals.

\begin{tabular}{cccccc}
\hline \multicolumn{6}{c}{ Age Composition (n= 828) } \\
\hline $\begin{array}{cccccc}20 \text { or below } \\
5 \%\end{array}$ & $21-25$ & $26-30$ & $31-35$ & $36-40$ & Above 40 \\
\hline \multicolumn{7}{c}{ Distribution by Educational Attainment $(\mathrm{n}=828)$} \\
\hline \multirow{2}{*}{ Graduate } & Undergraduate & College & High & Middle & Elementary \\
$13.7 \%$ & $42.8 \%$ & $28.2 \%$ & $11.3 \%$ & $3.3 \%$ & $.7 \%$ \\
\hline
\end{tabular}

Table 2.

Ideal parity of the post-1980s generation.

\begin{tabular}{ccc}
\hline $\begin{array}{c}\text { Characteristics of } \\
\text { Respondents }\end{array}$ & Ideal Parity & 95\% Standard Error \\
\hline Migrants & 1.27 & .07 \\
Non-migrants & 1.25 & .06 \\
Ethnic Minority & 1.09 & .10 \\
Non-minority & 1.27 & .05 \\
Beijing & 1.42 & .11 \\
Puyang & 1.06 & .03 \\
\hline
\end{tabular}


This finding was very interesting. The ethnic minorities were given the privilege to have more than one child, but it seemed that factors other than policy privilege accounted for their fertility desire. Furthermore, the ideal number of children was higher in Beijing than in Puyang.

The choice of ideal parity is a complex decision making process that results from many factors, such as skyrocketing housing prices, high costs of child-raising and education, opportunity costs of bearing children, peer pressure, aspiration for personal achievement, and drastic competition at work. The open ended questions in the survey helped collect information on the major determinants of fertility behaviors. The most frequently cited determinant, according to the survey respondents, was the economic ability to raise children. $57 \%$ of the post1980s respondents considered economic capability as the most important determinant of their ideal parity. The second most frequently cited factor was China's family planning policies. $26 \%$ of the post-1980s respondents indicated that family planning policies affected their fertility decision. Upon being asked "Would you like to have more children if you had a substantial improvement in economic condition?” $34.2 \%$ of the post-1980s indicated an interest in having more children. On being asked "Would you like to have more children if current family planning policies were revised to allow greater number of children?” $14.5 \%$ of the respondents would want more children as a response to the policy change. It is clear that economic factors are more influential in fertility desire than the family planning policies. Two other factors that accounted for ideal parity, although much less frequently cited, were Chinese traditional values on fertility, and pressure from parents.

\section{Gender Preference}

The findings indicate that the new generation of China's child-bearing adults left the traditional attitudes of son preference behind. Among the post-1980s who desired one child, nearly half respondents indicated no preference on child's gender. There was no strong preference towards either gender although the migrants showed a slight preference for boys (Table 3).

For those who desired two children, $79 \%$ preferred 1 boy and 1 girl, while $18 \%$ had no gender preference. The preference of the " 1 boy and 1 girl" combination was particularly highly represented by the migrants (88.9\%), compared to the non-migrants (69.7\%) (Table 3). Upon being asked "How would you manage to have two children under the current one child policy in urban China?" many of the respondents indicated that they were allowed to have two children because both husbands and

Table 3.

Gender preference of the post-1980s generation, by ideal parity.

\begin{tabular}{cccc}
\hline & Gender Preference & Non-migrants & Migrants \\
\cline { 2 - 4 } Ideal & Boy & $27.2 \%$ & $30.8 \%$ \\
Parity =1 & Girl & $28.1 \%$ & $22.3 \%$ \\
& No Preference & $44.7 \%$ & $46.9 \%$ \\
\hline & Gender Preference & Non-migrants & Migrants \\
\cline { 2 - 4 } Ideal & 2 Boys & $.0 \%$ & $.0 \%$ \\
Parity =2 & 2 Girls & $6.1 \%$ & $.0 \%$ \\
& 1 Boy and 1 Girl & $69.7 \%$ & $88.9 \%$ \\
& No Preference & $24.2 \%$ & $11.1 \%$ \\
\hline
\end{tabular}

wives were the only child of their family. Among those who were not the only child, there were special strategies cited to "beat-the-system”, such as giving the second birth abroad, and giving the second birth in China and ready to pay for the fine.

The major determinants of the gender preference were also investigated. Based on cited frequencies, the most cited reasons for preference for boys include: 1) the traditional idea that sons are the pillar of the family, 2) the belief of bringing up sons to support parents in old age, 3) the Chinese ideology of family continuation via male descendents, 4) raising a boy is easier than raising a girl, and 5) parents look forward to a grandson.

The most frequently cited reasons for preference for girls include the following: 1) girls are considerate, like mom's "warm jacket”; 2) girls tend to take care of parents in old age very well; 3) girls are obedient and save parents a lot worries; 4) it is a blessing to have girls, and 5) the cost of raising a girl is relatively low, particularly at the time of marriage when the groom's family prepares and is responsible for betrothal gifts.

\section{Use of Fetal Ultrasound}

With respect to the potential use of fetal ultrasound or other advanced technology, over $94 \%$ of the post-1980s respondents mentioned that they would use fetal ultrasound examination to check the health and wellness of the fetus. About $46 \%$ of them indicated that they wanted to know the sex of the fetus via ultrasound examination. In China it is illegal for the ultrasound technician and doctor to reveal the gender of the fetus, but many ultrasound machines are now in illegal or private clinics, so that people can have ultrasounds done in secret. Being asked if they wanted to determine the sex of the fetus via ultrasound in case it became legal, over three quarter of them said "yes". Upon being asked "What if the gender determined by ultrasound is not the preferred one?" 95\% of the respondents said they would still keep and raise the child, and $4 \%$ indicated that they would raise the child but try to have an additional baby that fits their preference. $1 \%$ of them indicated that they would choose to have a sex-selective abortion.

\section{Concluding Discussion}

Based on a questionnaire survey, this study is one of the first investigations on the fertility desire and gender preference of the post-1980s generation in urban China. The post-1980s individuals indicated a very low ideal parity. The most important determinant was China's family planning policies for $26 \%$ of the respondents, and economic factors for $57 \%$ of them. About half of the respondents who desired one child indicated no gender preference, and $79 \%$ of those who desired two children preferred the 1-boy-\&-1-girl combination. With respect to potential ultrasound utilization, the large majority indicated an intention to use ultrasound to check fetus wellness. Nearly half of them hoped that ultrasound technicians could disclose the gender of the fetus, which has been illegal in China.

The main findings suggest that the younger generation of Chinese value more on the quality of care of children than on the quantity or gender of children. Moreover, the fertility desire of the post-1980s implies that the urban areas of China have been experiencing a transition from a top-down governmental promoted (if not forced) fertility decline to a bottom-up individual voluntary choice of low fertility. Furthermore, the results of the research imply that socioeconomic factors are more influential than family planning policies in fertility choice. How- 
ever, as one of the basic national policies in China, the one child policy continues to play an important role in checking population, especially for the urban residents who desire more children, not mention the many families in the vast rural areas of China that demand greater number of labor.

China's situation today is tremendously different from the context in which the one-child policy was initiated several decades ago. In the context of below replacement fertility for over 20 years, trend of population ageing, and changing economic, social, and cultural environment, the findings of this study suggest that a relaxation of the one-child policy is unlikely to result in a substantial increase in fertility in urban China. On the contrary, step-by-step relaxations of the family planning policies, such as the strategy of "demographic soft landing” suggested by Zeng (2007), will tend to lead to a small and gradual bounce-back of the fertility. This slight or moderate fertility increase will be highly beneficial for China as it helps to reduce the negative consequences of population ageing and gender imbalance.

\section{Acknowledgements}

The author is very thankful to the dedication and hard work of the editors and anonymous reviewers. The author takes the full responsibility for the opinions expressed in this paper.

\section{REFERENCES}

Arnold, F., \& Liu, Z. (1986). Sex preference, fertility, and family planning in China. Population and Development Review, 12, 221-246. http://dx.doi.org/10.2307/1973109

Chu, J. H. (2001). Prenatal sex determination and sex-selective abortion in rural central China. Population and Development Review, 27, 259-281. http://dx.doi.org/10.1111/j.1728-4457.2001.00259.x

Gu, B., Wang, F., Guo, Z., \& Zhang, E. (2007). China’s local and national fertility policies at the end of the twentieth century. Population and Development Review, 33, 129-147. http://dx.doi.org/10.1111/j.1728-4457.2007.00161.x

Liang, Q., \& Lee, C. F. (2006). Fertility and population policy: An overview. In D. L. Poston Jr., et al. (Eds.), Fertility, family planning, and population policy in China (pp. 8-19). New York: Routledge.

Veeck, G., Pannell, C. W., Smith, C. J., \& Huang, Y. (2011). China's geography: Globalization and the dynamics of political, economic, and social change (2nd ed.). Lanham, MA: Rowman and Littlefield Publishers.

Wang, W. (2005). Son preference and educational opportunities of children in China-“I wish you were a boy!” Gender Issues, 22, 330.

Whyte, M. K., \& Gu, S. (1987). Popular response to China’s fertility transition. Population and Development Review, 13, 471-493. http://dx.doi.org/10.2307/1973135

Yan, Y. (2003). Private life under socialism: Love, intimacy and family change in a Chinese village, 1949-1999. Stanford, CA: Stanford University Press.

Zeng, Y. (2007). Options of fertility policy transition in China. Population and Development Review, 33, 215-246. http://dx.doi.org/10.1111/j.1728-4457.2007.00168.X

Zeng, Y., Ping, T., Gu, B., Yi, X., Li, B., \& Li, Y. (1993). Causes and implications of the recent increase in the reported sex ratio at birth in China. Population and Development Review, 19, 283-302. http://dx.doi.org/10.2307/2938438

Zhang, L., Feng, X., \& Zhang, Q. (2006). Changing patterns of desired fertility. In D. L. Poston Jr., et al. (Eds.), Fertility, family planning, and population policy in China (pp. 89-109). New York: Routledge.

Zhu, W. X., Lu, L., \& Hesketh, T. (2009). China's excess males, sex selective abortion, and one child policy. British Medical Journal, 338, b1211. http://www.bmj.com/content/338/bmj.b1211 